\title{
5S Conditions and Improvement Methodology in Apparel Industry in Pakistan
}

\author{
Hammad Saeed Shamsi \\ HIESS, Hamdard Univeristy, Pakistan
}

\begin{abstract}
The study has been taken after studying for 3 months at ten (10) different apparel industries in Pakistan. For development of textile and apparel sector of Pakistan a study has been conducted in apparel sector which is contributing on a very large scale in Pakistan export. The methodology that was adopted was started with making of a 5S committee and trained them over the 5S concept in detail. After training, an initial audit conducted and recorded the situation requiring 5S. After having the pictorial evidences, build an action plan to improve the situations. Thus in the end record the changes and standardize the process by putting it into an SOP. Thus the implementation of the concept can bring improvements in compliance and efficient workflow due to lesser machine breakdowns, lower defect rates, reduced inventory and effective problem visualization and addressing them before they aggravate.
\end{abstract}

Keywords: 5S, 5S Housekeeping, 5S in Pakistan, 5S in textile industry, 5S methodology

\section{Introduction}

According to the Pakistan Textile Journal, Pakistan is one of the top ten textile exporters. And with recent changes in law showing continuous increasing trend in textile export of Pakistan. It has a growth of about 30.8 percent according to Federal Bureau of Statistics. But on other hand Pakistan is in close competition with China, India, Srilanka and Bangladesh. To keep the market in hand it is required to adopt the modern management techniques for cost cutting and profit enhancement. Unfortunately most of the textile industry despite of having a very busy and healthy business activities don't look towards business excellence methods. This causing them extra cost, heavy wastages, price increase and quality issues.

Keeping this problem in mind there are various steps have been taken on government level to intact private sector updated about the current development around the world. Green Productivity, Bench Marking, Solid and Liquid Waste Management, deployment of QMS and using technology to perform the entire function in less time and with more productivity are few steps which have been proposed to the textile sector.

$5 \mathrm{~S}$ is also a known method of reducing waste, increasing productivity and clear visibility of non conformances at workplace. Evolved in Japan, $5 \mathrm{~S}$ has been adopted worldwide to transform the working condition towards excellence. The methodology has 5 major steps each of the step starting with a Japanese word which gives a sound of "S" therefore known as $5 \mathrm{~S}$. Those steps are:

$\begin{array}{llll}1- & \text { SEIRI } & \text { means } & \text { SORTING } \\ 2- & \text { SEITON } & \text { means } & \text { SET IN ORDER } \\ 3- & \text { SEISO } & \text { means } & \text { SHINE } \\ 4- & \text { SEIKETSU } & \text { means } & \text { STANDARDIZE } \\ 5- & \text { SHITSUKE } & \text { means } & \text { SUSTAIN }\end{array}$

The above system needs to be implemented in-order to get the desired results.

\section{Apperal Industry}

Statistics given by Pakistan Ready Made Garments Manufacturers and Exporters Association Pakistan textile exports reaches upto USD 6 billion quarterly. Major contribution if from apparel industry which itself cover over USD 4 billion per quarter. Keeping this in mind it is required to equip the industry with the current management and waste reduction techniques.

An typical apparel manufacturing unit have the following departments.

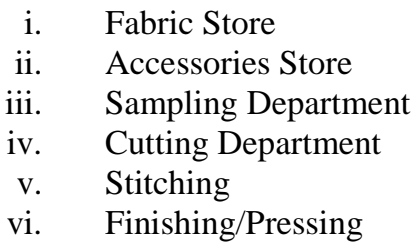


vii. Packing

viii. Office Area.

Usually it is seen in entire industry that factory management is not bothered about $5 \mathrm{~S}$ and unaware of its outcomes and benefits. It has been observed from the entire factory physical position and practices that millions is being wasted by the factory due to poor $5 \mathrm{~S}$ practices that need to be encountered.

\section{Improvement Methodology}

i. Making of 5S committee making sure the representation of all functional areas of factory - Time Duration 1 hour.

ii. Training of the committee over 5S philosophy and 5S auditing technique - Time Duration 1.5 days

iii. Site physical visit with committee, taking real time photographs as evidences of the places that needs improvement and the areas already considered as good examples of 5S. Tag the places that needs improvement with SEIRI, SEITON and SEISO tags as Figure 1- Time Duration 0.5 day.

iv. Tasks will be assigned to the respective persons of the departments where improvements are required.

v. Admin person will be responsible for arranging the resources for the committee like paint, spray, floor markers, tapes, tags and man power as loader and janitorial staff.

vi. At the end of the proposed period repeat the step no (iii) and take photographic evidences of improvements and remove tags.

vii. Repeat the activity periodically to sustain the improvements.

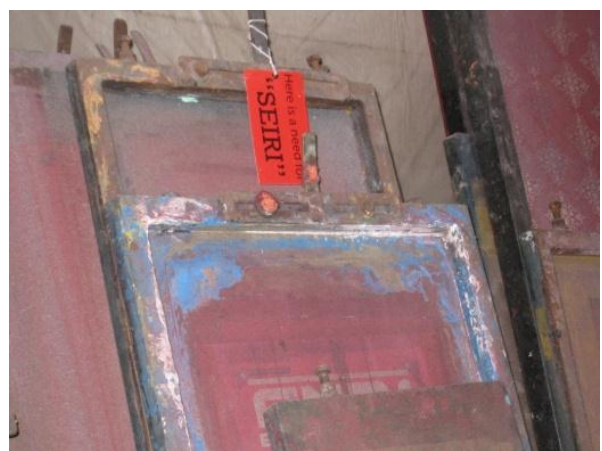

Figure 1- Tags are used to identify the places where a particular $5 \mathrm{~S}$ activity is required. Change the tag color for each activitylike Red for SEIRI, BLUE for SEITON and Green For SEISO.

Formats and SOPs are also introduced to log the problems and jot down the details. Two formats has been introduced in all the section. First was to write down the good points w.r.t. $5 \mathrm{~S}$ and second was to log the problems. Figure $2 \&$ Figure 3 are the examples of those formats.

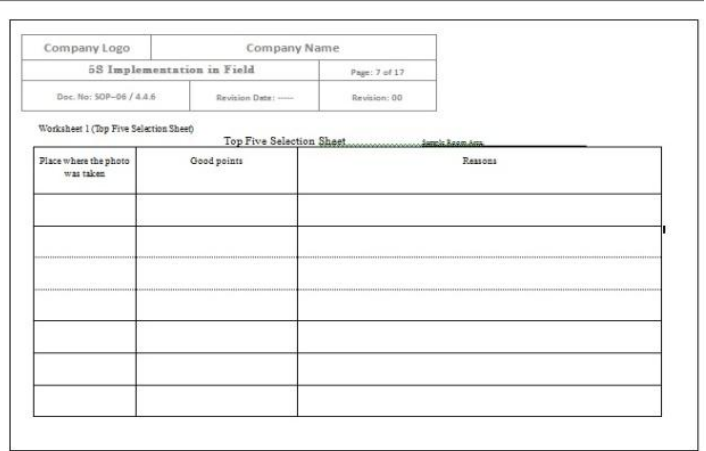

Figure 2- This format is being given to each down the good points w.r.t. $5 \mathrm{~S}$

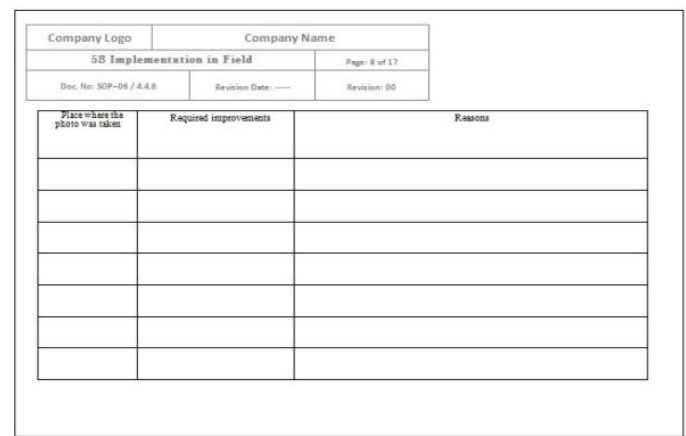

Figure 3- Situations requiring $5 \mathrm{~S}$ will be dept to jot noted down here.

\section{Problems Identification and Its Causes}

Problems can be indentified after completing the initial audit activity. Those problem falls under 1 category of 5S. Summary of the problems is shown into TABLE 1. 


\begin{tabular}{|l|l|l|l|l|l|l|l|l|}
\hline Problems & $\begin{array}{l}\text { Sample } \\
\text { Dept }\end{array}$ & Stores & Cutting & Stitching & Finishing & Packing & $\begin{array}{l}\text { Office } \\
\text { Area }\end{array}$ & $\begin{array}{l}\text { Action } \\
\text { Required }\end{array}$ \\
\hline $\begin{array}{l}\text { Unnecessary } \\
\text { Items }\end{array}$ & Yes & Yes & No & Yes & Yes & Yes & Yes & Seiri \\
\hline $\begin{array}{l}\text { Leftover } \\
\text { Present }\end{array}$ & Yes & Yes & Yes & Yes & Yes & Yes & No & Seiri \\
\hline $\begin{array}{l}\text { Rejection } \\
\text { On Floor }\end{array}$ & No & Yes & Yes & Yes & No & Yes & No & Seiri \\
\hline $\begin{array}{l}\text { Floor } \\
\text { Marking }\end{array}$ & Partial & No & Partial & Partial & No & No & No & Seiton \\
\hline Labels & No & No & No & No & No & No & No & Seiton \\
\hline Trolleys & Partial & Yes & No & Partial & No & No & No & Seiton \\
\hline Sub Store & No & No & No & No & No & No & No & Seiton \\
\hline $\begin{array}{l}\text { Visual } \\
\text { Controls }\end{array}$ & No & No & No & No & No & No & No & Seiton \\
\hline $\begin{array}{l}\text { Pathways } \\
\text { Defined }\end{array}$ & No & No & No & No & No & No & No & Seiketsu \\
\hline $\begin{array}{l}\text { Racks And } \\
\text { Bins }\end{array}$ & Yes & Yes & No & No & No & Yes & Yes & Seiton \\
\hline $\begin{array}{l}\text { Dust And } \\
\text { Stains }\end{array}$ & Yes & Yes & Yes & Yes & Yes & Yes & Yes & Seiso \\
\hline Visible Sops & No & No & No & No & No & No & No & Seiketsu \\
\hline $\begin{array}{l}\text { Workers } \\
\text { Training } \\
\text { Over 5s }\end{array}$ & No & No & No & No & No & No & No & Shitsuke \\
\hline $\begin{array}{l}\text { Files } \\
\text { Arrangement }\end{array}$ & No & No & No & No & No & No & No & Seiton \\
\hline
\end{tabular}

Table 1- showing the combined status of each department of all the companies the study has been performed. These are generic problems and for a particular factory the no of problem can be increased or decreased.

Except the above there are few more problems that can be commonly identified in almost every factory of the region and those are:
i. Dirty washrooms for labor
ii. No proper dining areas
iii. Spitting problems
iv. $\quad$ No uniform for workers
v. Safety negligence etc.
vi. $\quad$ No periodic waste thrown activity and SOP is defined

After logging the problems it is required to held a brain storming sessions by developing a fishbone diagram for each major problem. It will become a bible for each non conformances need to be correct down in future also. It is required to call the functional incharges of all the sections and put the problem infront of them to identify the possible causes of the problem. Make sure all the possible causes must be note down without letting down anyone's idea. Then enquire about each possible cause to identify the most likely hood of the problem. Once the actual reason sorted out, take counter measure actions that is required for particular problem. Figure 4- Shows a FISH BONE diagram for on of the problem stated above.

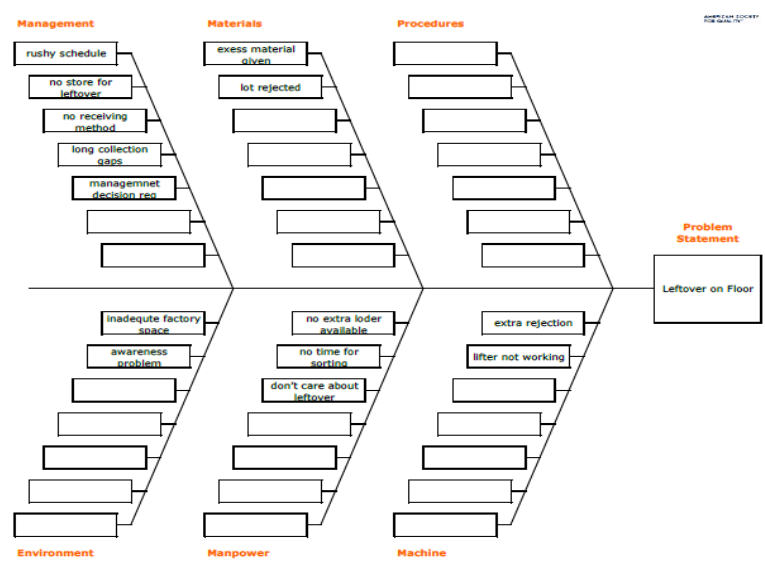

Figure 4 - Fishbone diagram for one of the problem stated. In all the possible causes collected it is needed to investigate all cause and sort the most contributing cause. 


\section{Counter Measures and Improvements}

The actual problems and their counter measures need to be logged in order to have a systematic approach towards the problems solutions. Moreover it is required to allocate required resources to encounter a particular problem and getting approvals from top management where ever needed. Table 2 - Shows a format of noting down the problems and its improvement measures.

\begin{tabular}{|c|c|c|c|c|c|}
\hline \multirow[t]{2}{*}{ Issues } & \multicolumn{3}{|c|}{ Improvement Measures (Ideas) } & \multicolumn{2}{|c|}{ Expected effect } \\
\hline & Primary Measure & Secondary Measure & Tertiary Measure & Assessment & Ranking \\
\hline & & & & & \\
\hline & & & & & \\
\hline & & & & & \\
\hline & & & & & \\
\hline & & & & & \\
\hline & & & & & \\
\hline & & & & & \\
\hline & & & & & \\
\hline & & & & & \\
\hline & & & & & \\
\hline & & & & & \\
\hline & & & & & \\
\hline & & & & & \\
\hline & & & & & \\
\hline & & & & & \\
\hline & & & & & \\
\hline & & & & & \\
\hline & & & & & \\
\hline & & & & & \\
\hline
\end{tabular}

Table 2-It is important to document the problems inorder to identify the resources and make a action plan for future. Some actions may need management approval and this document will make it easy to get an approval with proper presentation.

Descriptions of the content that need to be inserted in TABLE 2 are as under.

i- $\quad$ Issues - note down the actual sorted out cause which comes after brain storming session

ii- Primary measure - write the immediate action that can be happen to improve the situation.

iii- Secondary measure - write down the action that required extra resources and time to prevent the recurrence of the problem

iv- Tertiary measure - measure that need to be taken for prevention of such problem

v- Assessment - assess the improved situation and comments accordingly

vi- Ranking - make a system of ranking for the improvement taken and give the marks as per validity of the counter measure.

\subsection{Requirement of Initial Resources}

i. Loaders

It is required some resources to improve the current situation. Those include:

ii. Janitorial Staff

iii. Paint material

iv. Marking tape

v. Spray colors

vi. Color papers for printing

vii. Green board(s)

viii. Sticker papers

ix. Acrylic name plates for departments and sections

$\mathrm{x}$. Designated places for keeping materials at different stages. 


\section{Results}

Results need to be noted down and pictorial evidences should be collected inorder to present and motivate the employees. Onsite verification by the auditor to remove the tags and take pictures. These pictures can be shown at $5 \mathrm{~S}$ board. The following areas can have a immediate improvement by using $5 \mathrm{~S}$ methodology.

\subsection{Floor Marking and Area Identification}

\section{Production Line}

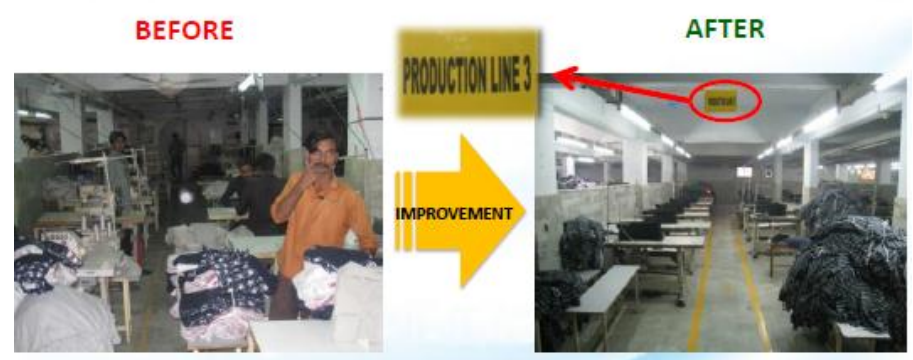

Description of 5 S improvement:

All production lines are re aligned, cleaned and labeled. Moreover all the sub department of production is also being labeled

Figure 5

\subsection{Sample Department}

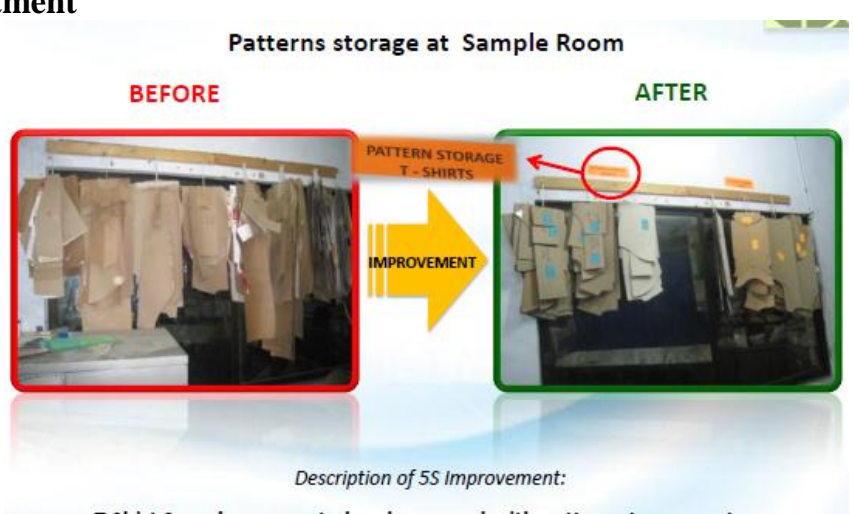

T Shirt Samples are sorted and arranged with pattern storage system

Figure 6

\subsection{Cutting Section}

\section{Cutting Department}

BEFORE

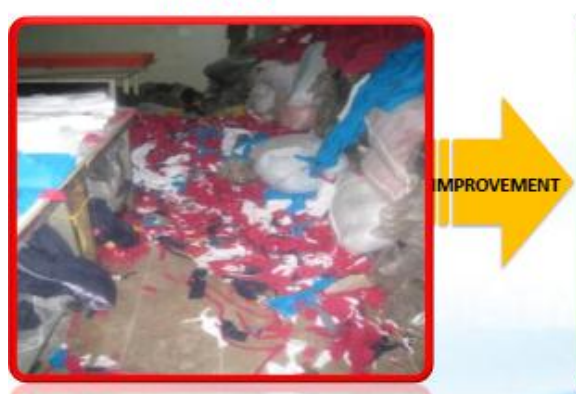

AFTER

Description of $5 \mathrm{~S}$ Improvement:

Figure 7

Floor has been cleaned, marked. Raw material stacked in proper manner. 


\subsection{Sample Department}

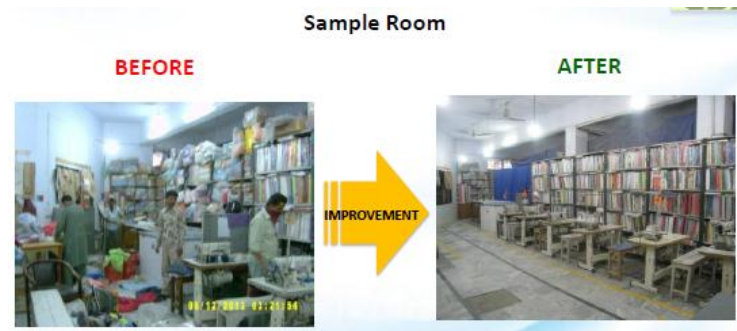

Description of 5 I Improvement:

Sample room has been turned into a model 55 place.

Figure 8

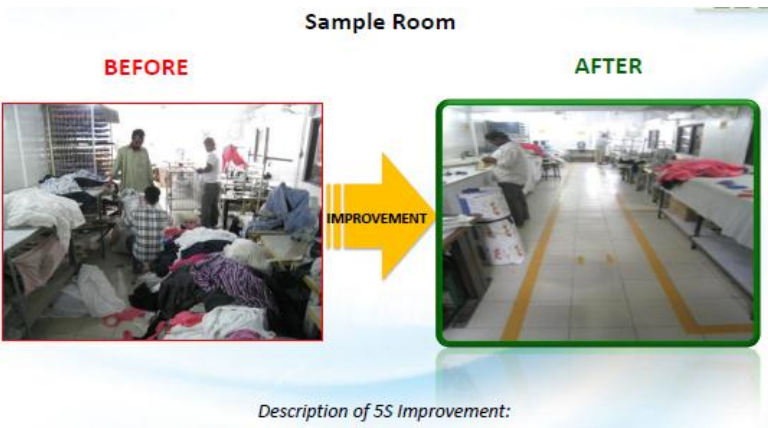

The Sample department was made a model $5 \mathrm{~S}$ place where wastages removed, patterns has been marked, places are labeled and floor has been

Figure 9

\subsection{Store}

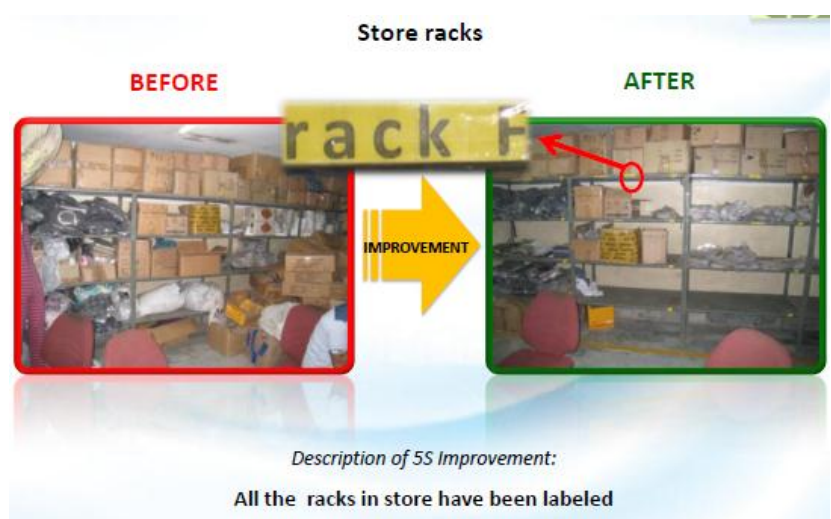

Figure 10

\subsection{Office Filing}

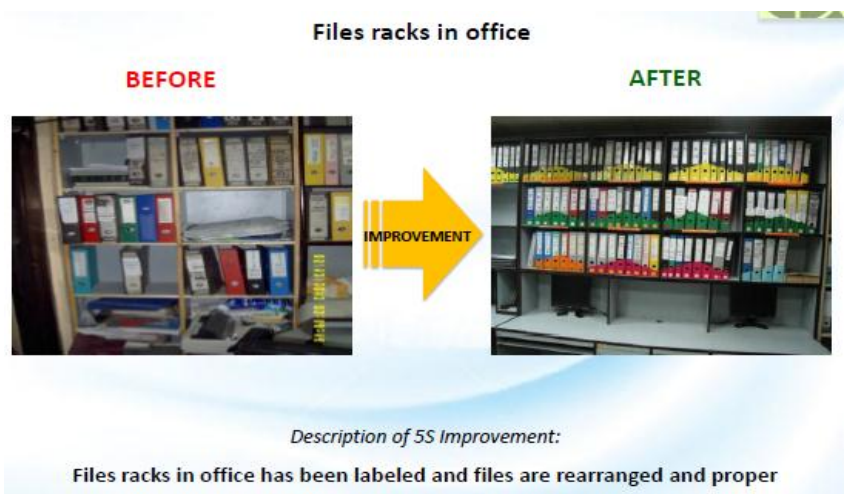

labeling and area identification.

Figure 11 


\subsection{Information Area and Notice Boards}

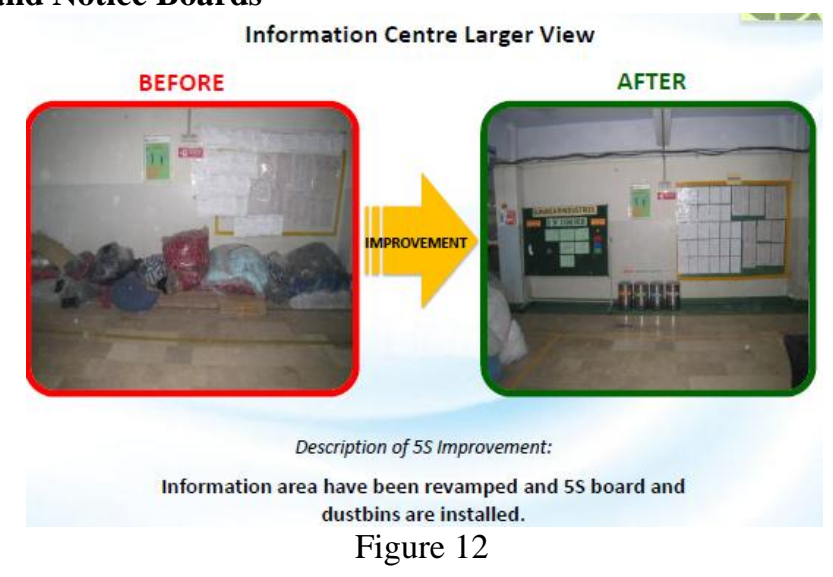

\section{Conclusion}

The above activity was performed on ten (10) different factories and through 5S Japanese way of housekeeping some great results come in very short period of time. It is required to continue the audit activity on regular basis and allocated resources and budget to maintain the $5 \mathrm{~S}$. The $5 \mathrm{~S}$ committee need to propagate the philosophy to every employee by training and awareness program and a continuous improvement activity is required to enhance the production and reduce the wastages. It is also recommended to introduce the reward and penalization system to motivate the employees over $5 \mathrm{~S}$. It can be also a part of yearly appraisal. $5 \mathrm{~S}$ is a proven methodology and give remarkable results all over the world. Pakistan industry need to adopt it as a initial step toward modern management approaches.

\section{References}

[1] Adnan Maroof Khan and Md. Mazedul Islam, Application of 5S System in the Sample Section of an Apparel Industry for Smooth Sample Dispatch, Research Journal of Management Sciences, Vol. 2(7), 28-32, July (2013), ISSN 2319-1171

[2] www.prgmea.org, Pakistan readymade garments manufacturers and exporters association, Pakistan

[3] www.rcci.org.pk, Rawalpindi chamber of commerce and industry, Pakistan.

[4] www..org/sixsigma/2008/04/fishbone-cause-and-effect-diagram.xls 